\title{
Differential patterns of histone acetylation in inflammatory bowel diseases
}

\author{
Loukia G Tsaprouni ${ }^{1}$, Kazuhiro Ito ${ }^{1}$, Jonathan J Powell ${ }^{3}$, Ian M Adcock ${ }^{1 *}$, Neville Punchard ${ }^{2}$
}

\begin{abstract}
Post-translational modifications of histones, particularly acetylation, are associated with the regulation of inflammatory gene expression. We used two animal models of inflammation of the bowel and biopsy samples from patients with Crohn's disease (CD) to study the expression of acetylated histones (H) 3 and 4 in inflamed mucosa. Acetylation of histone $\mathrm{H} 4$ was significantly elevated in the inflamed mucosa in the trinitrobenzene sulfonic acid model of colitis particularly on lysine residues (K) 8 and 12 in contrast to non-inflamed tissue. In addition, acetylated H4 was localised to inflamed tissue and to Peyer's patches (PP) in dextran sulfate sodium (DSS)-treated rat models. Within the PP, H3 acetylation was detected in the mantle zone whereas $\mathrm{H} 4$ acetylation was seen in both the periphery and the germinal centre. Finally, acetylation of $\mathrm{H} 4$ was significantly upregulated in inflamed biopsies and PP from patients with CD. Enhanced acetylation of H4K5 and K16 was seen in the PP. These results demonstrate that histone acetylation is associated with inflammation and may provide a novel therapeutic target for mucosal inflammation.
\end{abstract}

\section{Introduction}

The cause of inflammatory bowel disease (IBD) remains unknown. The main forms of IBD are Crohn's disease and Ulcerative colitis. The main difference between Crohn's disease and UC is the location and nature of the inflammatory changes. Crohn's can affect any part of the gastrointestinal tract, from mouth to anus (skip lesions), although a majority of the cases start in the terminal ileum. Ulcerative colitis, in contrast, is restricted to the colon and the rectum [1]. It has been proposed that epithelial abnormalities are the central defect, and that they underlie the development of mucosal inflammation and its chronicity [2]. In some patients IBD can be effectively treated by enemas containing short chain fatty acids (SCFA) such as butyrate, propionate, and acetate [3] in combination with steroid treatment. The molecular mechanisms that lead to this response have not been well characterized.

Several rodent models of chronic intestinal inflammation share immunopathologic features with human IBD. The two most widely used models of experimental colitis are, the 2,4,-trinitrobenzene sulfonic acid (TNBS)

\footnotetext{
* Correspondence: ian.adcock@imperial.ac.uk

'Airways Disease Section, National Heart \& Lung Institute, Imperial College

London, Dovehouse Street, London, SW3 6LY, UK

Full list of author information is available at the end of the article
}

model of intestinal inflammation and the dextran sodium sulphate (DSS)-induced colitis model. DSSinduced colitis resembles ulcerative colitis with regard to its pathologic features. The TNBS induced colitis is an experimental model of intestinal inflammation that most closely resembles the histologic features of Crohn's disease $[4,5]$. It has recently been reported that distinctive disease-specific cytokine profiles were identified with significant correlations to disease activity and duration of disease in the two models. TNBS colitis exhibits a heightened Th1-Th17 response (increased IL-12 and IL-17) as the disease becomes chronic. In contrast, DSS colitis switches from a Th1-Th17-mediated acute inflammation to a predominant Th2-mediated inflammatory response in the chronic state $[6,7]$.

Two recent articles clearly show that the transcription factor NF-B signalling in intestinal epithelial cells plays a crucial role in controlling inflammatory responses and fighting infection in the gut $[8,9]$. In addition, p65 antisense oligonucleotides [10] and NF- $\kappa$ B inhibitors $[11,12]$ block inflammation in DSS induced colitis. NF- $\kappa \mathrm{B}$ enhances inflammatory gene expression by recruiting transcriptional co-activator proteins that have intrinsic histone acetyltransferase activity [13]. Remodelling of chromatin within the nucleus, controlled by the degree of acetylation/deacetylation of histone residues on the
C Biomed Central

(c) 2011 Tsaprouni et al; licensee BioMed Central Ltd. This is an Open Access article distributed under the terms of the Creative Commons Attribution License (http://creativecommons.org/licenses/by/2.0), which permits unrestricted use, distribution, and reproduction in any medium, provided the original work is properly cited. 
histone core around which DNA is coiled, is important in allowing access for transcription factor DNA binding and hence gene transcription. Nuclear histone acetylation is a reversible process and is regulated by a group of acetyltransferases (HATs) which promote acetylation, and deacetylases (HDACs) which promote deacetylation. HDAC inhibitors such as butyrate and TSA can function by triggering the NF- $\kappa \mathrm{B}$ response, resulting in enhanced expression of NF- $\kappa \mathrm{B}$-dependent inflammatory genes $[14,15]$. Non-selective HDAC inhibitors can ameliorate experimental colitis in mice by suppressing cytokine production, inducing apoptosis and histone acetylation [16] possibly relating to inflammatory cell survival although their precise mechanism of action is unclear $[17,18]$. The effect of the HDAC inhibitors could also be due to the large number of non-histone targets [18] including transcription factors such as $\mathrm{NF}-\kappa \mathrm{B}$, cytoskeletal proteins and cell cycle regulators thereby affecting not only inflammatory gene expression but cell proliferation and survival $[19,20]$.

$\mathrm{NF}-\kappa \mathrm{B}$-induced lysine residue-specific histone acetylation (K8 and K12) has been associated with up-regulation of inflammatory genes in some cells whereas gene induction by nuclear receptors such as the glucocorticoid receptor is linked to acetylation of different lysine residues [21]. In more recent studies, reduced dexamethasone-induced transactivation in $\mathrm{CD} 8^{+} \mathrm{T}$ cells compared to $\mathrm{CD} 4^{+} \mathrm{T}$ cells was shown and was related to attenuated $\mathrm{H} 4$ lysine 5 acetylation in response to dexamethasone [22]. The importance of specific lysine histone acetylation is also stressed by Fraga and colleagues who showed that global loss of acetylation lysine 16 and trimethylation of lysine 20 of histone 4 is a common hallmark of human tumour cells [23]. Here, we investigate the pattern of histone 4 acetylation and its localization in two in vivo models of inflammation and in patients with Crohn's disease.

\section{Experimental Procedures Animal tissue samples}

Two models of experimental colitis were chosen in order to depict different pathologic features associated with Crohn's disease and Ulcerative colitis and to possibly compare different patterns of histone acetylation with different pathologic features. The 2,4,-trinitrobenzene sulfonic acid (TNBS) model of intestinal inflammation, based on that of Morris et al., was used [24]. Tissue was kindly provided by UCB, Slough, UK. The studies were performed in accordance with the UK Home office procedures. Eighteen male Sprague-Dawley rats (median weight of $337.5 \mathrm{~g}$ ) and eighteen male Lewis rats (media weight 205 g) (Charles River, UK) were used. All rats were allowed free access to standard pellet chow and water ad libitum. They were randomly assigned into two groups. The first group was treated intra-rectally with $30 \mathrm{mg}$ of TNBS in 30\% w/v ethanol, on day zero. The second, Sham operated (control), was treated with $30 \%$ ethanol alone. The animals were sacrificed on day seven and tissue was resected from two separate areas of the large intestine- two centimetres distal to the caecum (proximal colon) and three centimetres proximal to the anus (distal colon). Within the TNBS treated group these two areas constituted the inflamed (distal) and non-inflamed (proximal) regions of the colon. For the dextran sodium sulphate (DSS)induced colitis model, colonic inflammation was induced to Spraque-Dawley and Lewis rats by administration of 5\% DSS (molecular mass, $40 \mathrm{kDa}$, ICN Biomedical, Aurora, $\mathrm{OH}$ ) in filter purified (Millipore Bedford, MA) drinking water for 8 days as previously described [25].

\section{Human tissue samples}

Human tissue was collected during routine surgery, or routine endoscopy procedures at St. Thomas' hospital with appropriate ethical approval. Biopsies were collected from 12 patients aged between 18-57 yrs with Crohn's disease from macroscopically inflamed or noninflamed regions of the large and small intestine or were isolated Peyer's patches and were grouped to inflamed and non-inflamed based on macroscopic examination. The patients were undergoing treatment with sulfasalazine and/or antibiotics (ampicillin, tetracycline). None of the patients were smokers. Inflammation was graded using a previously validated scoring system according to the cellularity of the lamina propria and the severity of changes in the enterocytes and crypts. In this system, grade 0 represents no inflammation, termed 'noninflamed', and grade 3, represents severely inflamed biopsies. Any samples from macroscopically noninvolved areas that showed evidence of microscopic inflammation were excluded from analysis. Samples of bowel were also taken from 11 patients undergoing intestinal resection for carcinoma of the colon, to serve as non-inflamed controls. Biopsies were collected at least $4 \mathrm{~cm}$ from macroscopic disease [26]. All samples were snap frozen in liquid nitrogen immediately after excision. Tissue was subsequently maintained in a frozen state at $-80^{\circ} \mathrm{C}$ until use.

\section{Preparation of tissue sections}

For microscopic analysis, the biopsies were fixed in $4 \%$ (w/v) paraformaldehyde/PBS for $3 \mathrm{~h}$ at $4^{\circ} \mathrm{C}$, cryoprotected in sterile $4 \%(\mathrm{w} / \mathrm{v})$ sucrose $/ \mathrm{PBS}$ at $4^{\circ} \mathrm{C}$ overnight, mounted in OCT mountant (BDH, Atherstone, UK) on labeled cork discs and frozen in liquid nitrogen-cooled isopentane. Tissue samples were stored at $-80^{\circ} \mathrm{C}$. The tissues were sectioned $(8 \mu \mathrm{m})$, mounted and the slides allowed to air-dry, covered in foil and stored at $-20^{\circ} \mathrm{C}$. 


\section{Direct Histone Extraction}

Histones were extracted from nuclei, as previously described by Ito et al., [27]. In brief, tissue was frozen in liquid nitrogen and minced in a pestle and mortar. The homogenate was collected in $100 \mu \mathrm{l}$ PBS, microcentrifuged for $5 \mathrm{~min}$ and then extracted with ice-cold lysis buffer $(10 \mathrm{mM}$ Tris-HCL, $50 \mathrm{mM}$ sodium bisulfite, $1 \%$ Triton X-100, $10 \mathrm{mM} \mathrm{MgCl}_{2}, 8.6 \%$ sucrose, complete protease inhibitor cocktail [Boehringer-Mannheim, Lewes, UK]) for $20 \mathrm{~min}$ at $4^{\circ} \mathrm{C}$. The pellet was washed in buffer three times (centrifuged at 8.000 $\mathrm{rpm}$ for $5 \mathrm{~min}$ ) and the nuclear pellet was washed in nuclear wash buffer $(10 \mathrm{mM}$ Tris-HCL, $13 \mathrm{mM}$ EDTA) and resuspended in $50 \mu \mathrm{l}$ of $0.2 \mathrm{~N} \mathrm{HCL}$ and $0.4 \mathrm{~N} \mathrm{H}_{2} \mathrm{SO}_{4}$ in distilled water. The nuclei were extracted overnight at $4^{\circ} \mathrm{C}$ and the residue was microcentrifuged for $10 \mathrm{~min}$. The supernatant was mixed with $1 \mathrm{ml}$ ice-cold acetone and incubated overnight at $-20^{\circ} \mathrm{C}$. The sample was centrifuged for $10 \mathrm{~min}$, washed with acetone, dried and diluted in distilled water. Protein concentrations were determined using a Bradford method based protein assay kit (Bio-Rad, Hemel Hempstead, UK).

\section{Immunoblotting}

Isolated histones were measured by sodium dodecyl sulfate-polyacrilamide gel electrophoresis (SDS-PAGE) [28]. Proteins were size fractionated by SDS-PAGE and transferred to Hybond-ECL membranes. Immunoreactive bands were detected by ECL. 30-50 $\mu$ g of protein were loaded per lane. The following antibodies were used at a 1:1000 dilution: (pan-acetylated $\mathrm{H} 4$, pan-acetylated $\mathrm{H} 3$, H4-K5, H4-K8, H4-K12 and H4-K16 (all from Serotec, Oxford, UK). $\beta$-actin was used as internal control at a dilution of 1:10000 (Abcam, Cambridge, UK). The secondary antibody used was 1:4000 rabbit anti-goat or goat anti-rabbit antibody (Dako) linked to horseradish peroxidase. Bands were visualized by enhanced chemiluminescence $(E C L)$ as recommended by the manufacturer (Amersham Pharmacia Biotech, Little Chalfont, UK) and quantified using a densitometer with Grab-It and GelWorks software (UVP, Cambridge, UK). The individual band optical density values for each lane were expressed as the ratio with the corresponding $ß$-actin optical density value of the same lane.

\section{Immunohistochemistry}

The slides were fixed for $10 \mathrm{~min}$ in chilled acetone and allowed to air dry for a further 10 mins. They were then incubated for $1 \mathrm{hr}$ in Quench Endogenous Peroxidase $\left(3 \% \mathrm{H}_{2} \mathrm{O}_{2}\right.$ in PBS containing $0.02 \%$ Sodium Azide). Subsequently, they were washed $3 \times 5$ mins in PBS and pre-blocked with $5 \%$ normal swine serum (Serotec, Oxford, UK) for 20 mins. The slides were incubated with the primary antibody (pan-acetylated H4, panacetylated H3, H4-K5, H4-K8, H4-K12 and H4-K16 [Serotec, Oxford, UK]) diluted in PBS, at 1/100 dilution, for $2 \mathrm{hr}$. They were then washed twice for 5 mins in $\mathrm{PBS}$ and incubated with biotinylated swine anti-rabbit immunoglobulin G (IgG, DACO), 1/200 dilution, for $45 \mathrm{~min}$. Slides were washed in PBS, distilled water and counterstained in 20\% Harris haematoxylin for $10 \mathrm{sec}$. Finally, they were air-dried and mounted in DPX. Micrographs were captured using a light microscope (Leitz Biomed, Leica, Cambridge) linked to a computerized image system (Quantimet 500, Software Qwin V0200B, Leica) $[28,29]$.

\section{Statistics}

Results are expressed as mean \pm standard error of the mean (SE). A multiple comparison was made between the mean of the control and the means from each individual group by Dunnett's test by using SAS/STAT software (SAS Institute Inc., Cary, N.C.). We performed all statistical testing by using a two-sided $5 \%$ level of significance.

\section{Results}

Macroscopical characterisation of the intestine in a rat TNBS model of colitis

TNBS induced significant inflammation within the proximal and distal regions of the colon although the extent of inflammation was greater in the distal region (Figure 1A).

\section{Histone acetylation in inflamed and non-inflamed regions} of the colon in the rat TNBS model of colitis

TNBS induced a significant increase in pan histone 4 acetylation in the distal $(592 \pm 54 \%$ vs $135 \pm 24$ Sham operated animals, $\mathrm{p}<0.05)$ and the proximal regions of the colon $(315 \pm 39 \%$ vs $125 \pm 19 \%$ sham operated animals, $\mathrm{p}<0.05)$ with the inflamed distal region showing a greater increase (Figure 1B).

Acetylation of lysine $(\mathrm{K})$ residues 8 and 12 were significantly increased in both the inflamed distal (K8: $818 \pm$ 111 vs $138 \pm 19 \%$; K12: $741 \pm 64$ vs $121 \pm 34 \%$, both $\mathrm{p}<0.05)$ and less-inflamed proximal (K8: $546 \pm 50$ vs $100 \pm 21 \%$; K12: $533 \pm 69$ vs $100 \pm 26 \%$, both $\mathrm{p}<0.05)$ regions following TNBS treatment (Figure 2). However, the effect was significantly greater in the inflamed tissue than in the less-inflamed tissue for both K8 (818 \pm 111 vs $546 \pm 50 \%, \mathrm{p}<0.05)$ and $\mathrm{K} 12(741 \pm 64$ vs $533 \pm$ $69 \%, \mathrm{p}<0.05)$.

In contrast, there was no significant induction of $\mathrm{K} 5$ or K16 induction by TNBS in the inflamed distal region (Figure 2). Moreover, K5 (255 \pm 39 vs $100 \pm 15 \%$ Sham operated animals, $\mathrm{p}<0.05)$ and $\mathrm{K} 16(300 \pm 63$ vs $100 \pm$ $29 \%$ Sham operated animals, $\mathrm{p}<0.05)$ acetylation was enhanced in the non-inflamed proximal region. 


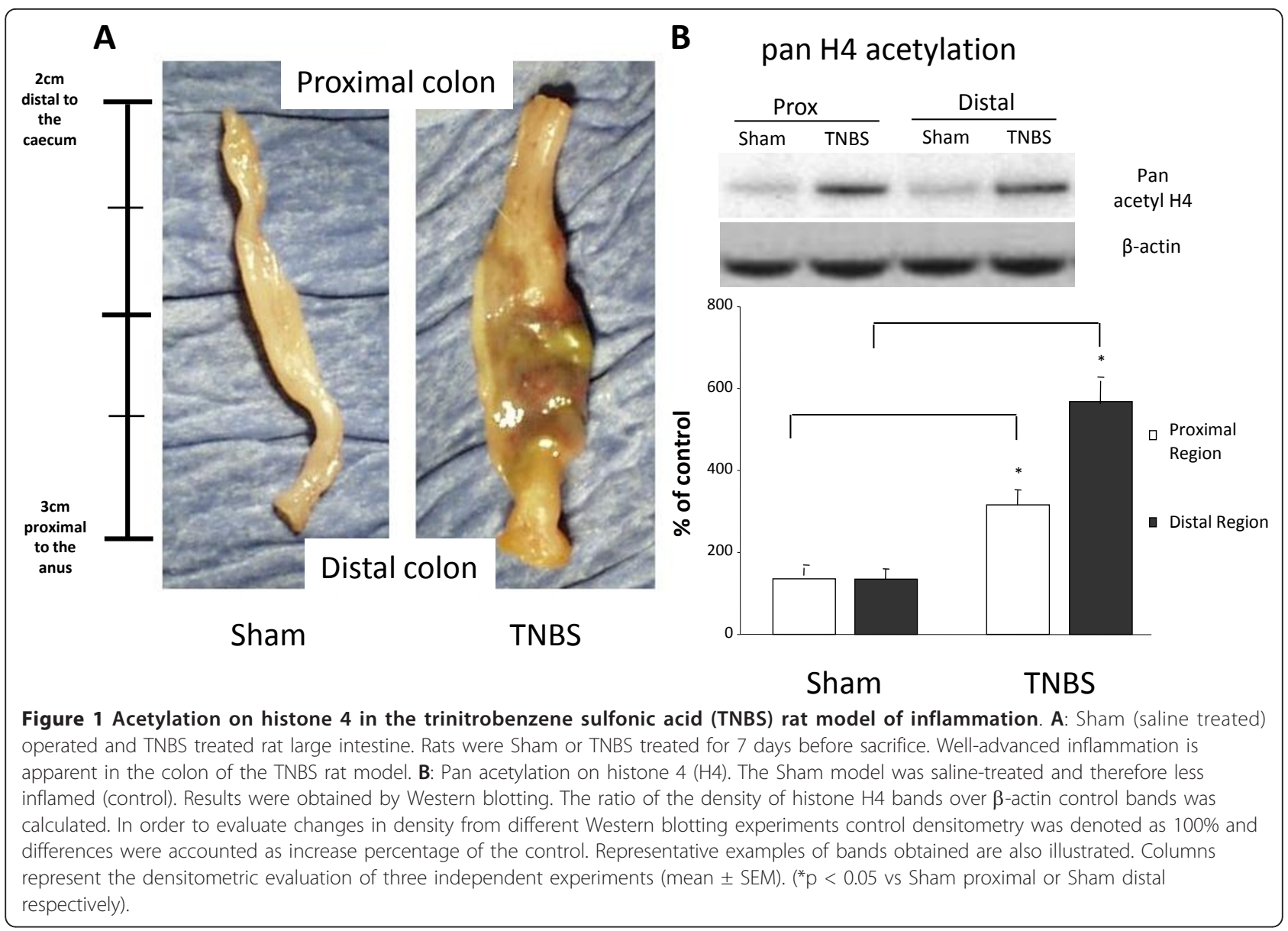

Localisation of acetylated histones 4 and 3 in DSS-treated animal models

Acetylation of both histones 4 and 3 was evident in non-DSS treated rats but this was enhanced in all inflamed areas, regardless of distinct positions in the colon, of both for Lewis rats (H4: $222 \pm 31$ DSS treated vs $100 \pm 31 \%$ non-DSS treated animals, $\mathrm{p}<0.05$; H3 $292 \pm 40$ DSS treated vs $100 \pm 13 \%$ non-DSS treated animals, $\mathrm{p}<0.05)$ and Spraque-Dawley rats (H4: $187 \pm$ 30 DSS treated vs $100 \pm 21 \%$ non-DSS treated animals, $\mathrm{p}<0.05$; H3 $361 \pm 36$ DSS treated vs $100 \pm 15 \%$ nonDSS treated animals, $\mathrm{p}<0.05$ ) (Figure 3 ). Similar results were obtained from Sprague-Dawley DSS-treated cells.

\section{Localisation of acetylated histones 4 and 3 in Peyer's patches}

We also investigated whether DSS-treatment would have an effect on histone acetylation in the Peyer's patches found in the small intestine. Acetylated histones are indicated by the brown colour in the micrographs. Pan acetylated H3 was situated in the mantle zone of Peyer's patches in DSS-treated Lewis and Sprague-Dawley rats in contrast to the more uniformed staining for acetylated histone 4 throughout the surface of Peyer's patches (Figure 3D).

\section{Specificity of histone 4 lysine acetylation in Peyer's patches after DSS treatment}

DSS induced acetylation of histone 4 lysines $\mathrm{K} 5$, K8, K12 and K16 in both rat strains (Figure 4). However, a greater induction was seen on K8 in both Lewis (414 \pm 51 DSS treated vs $100 \pm 23 \%$ non-DSS treated animals) and Sprague-Dawley rats $(1275 \pm 123$ DSS treated vs $100 \pm 18 \%$ non-DSS treated animals). Similar results were seen with K12 in both Lewis $(703 \pm 64$ DSS treated vs $100 \pm 14 \%$ non-DSS treated animals) and Sprague-Dawley rats $(1117 \pm 113$ DSS treated vs $100 \pm 27 \%$ non-DSS treated animals). K5 acetylation in Lewis rats $(346 \pm 17$ DSS treated vs $100 \pm 12 \%$ non-DSS treated animals) and Sprague-Dawley rats (263 \pm 22 DSS treated vs $100 \pm 16 \%$ non-DSS treated animals) was also induced albeit to a lesser extent. Our findings were similar for K16 acetylation in both Lewis (235 \pm 43 DSS treated vs $100 \pm 22 \%$ non-DSS treated animals) and Sprague-Dawley rats $(321 \pm 24$ DSS treated vs $100 \pm$ $26 \%$ non-DSS treated animals). 


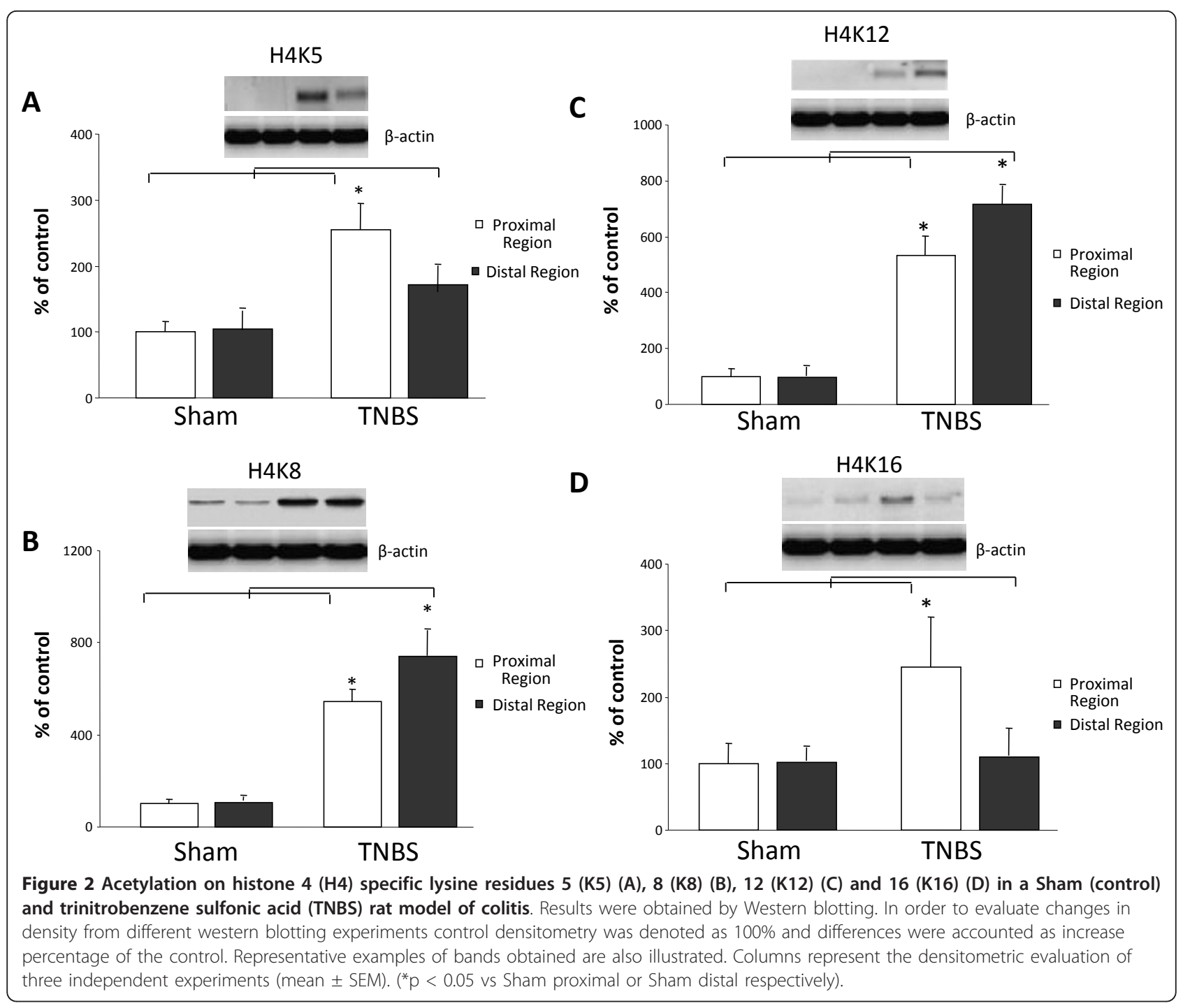

\section{Histone acetylation in Crohn's disease}

Acetylation on $\mathrm{H} 4$ was slightly induced in the noninflamed ileum of Crohn's disease patients. In contrast, $\mathrm{H} 4$ acetylation was significantly elevated in the inflamed regions (472 \pm 88 vs $100 \pm 34 \%$ control, p < 0.05) (Figure 5A). Peyer's patches from Crohn's disease patients also showed a significant increase in pan $\mathrm{H} 4$ acetylation $(382 \pm 29 \%)$ compared to the control non-inflamed tissue $(100 \pm 34 \%, \mathrm{p}<0.05)$ (Figure $5 \mathrm{~A}$ ). Levels of acetylated $\mathrm{K} 5$ were not significantly upregulated compared to control (Figure 5). More specifically, K8 acetylation was significantly induced compared to control samples in the inflamed regions $(527 \pm 44 \%$ vs $100 \pm 25 \%$ control tissue, $\mathrm{p}<0.05)$ and the non-inflamed CD samples (527 \pm $44 \%$ vs $195 \pm 42 \%$ non-inflamed CD, p < 0.05). In Peyer's patches from CD patients, K8 was significantly upregulated compared to control (488 $\pm 52 \%$ vs $100 \pm 25 \%$ control tissue, $\mathrm{p}<0.05$ ) (Figure 5).
Enhanced acetylation on K12 was detected in inflamed regions of CD compared to control (442 $\pm 54 \%$ vs $100 \pm$ $29 \%$ control tissue, $\mathrm{p}<0.05$ ) and non-inflamed CD tissue $(442 \pm 54 \%$ vs $223 \pm 38 \%$ non-inflamed IBD tissue, $\mathrm{p}<0.05)$. Similarly, enhanced acetylation on K12 was detected in Peyer's patches compared to control (429 \pm $65 \%$ vs $100 \pm 29 \%$ control tissue, $\mathrm{p}<0.05)$. Acetylation on lysine 12 was not significantly increased in noninflamed tissue compared to control. No changes in lysine 16 acetylation were observed in either inflamed or non-inflamed tissue from Crohn's disease patients. In the Peyer's patches, however, a significant elevation of acetylation on K16 was observed (Figure 5).

\section{Discussion}

Our results show that acetylation of histone $\mathrm{H} 4$ was significantly elevated in the inflamed mucosa in the TNBS model of colitis particularly on lysine residues (K) 8 and 


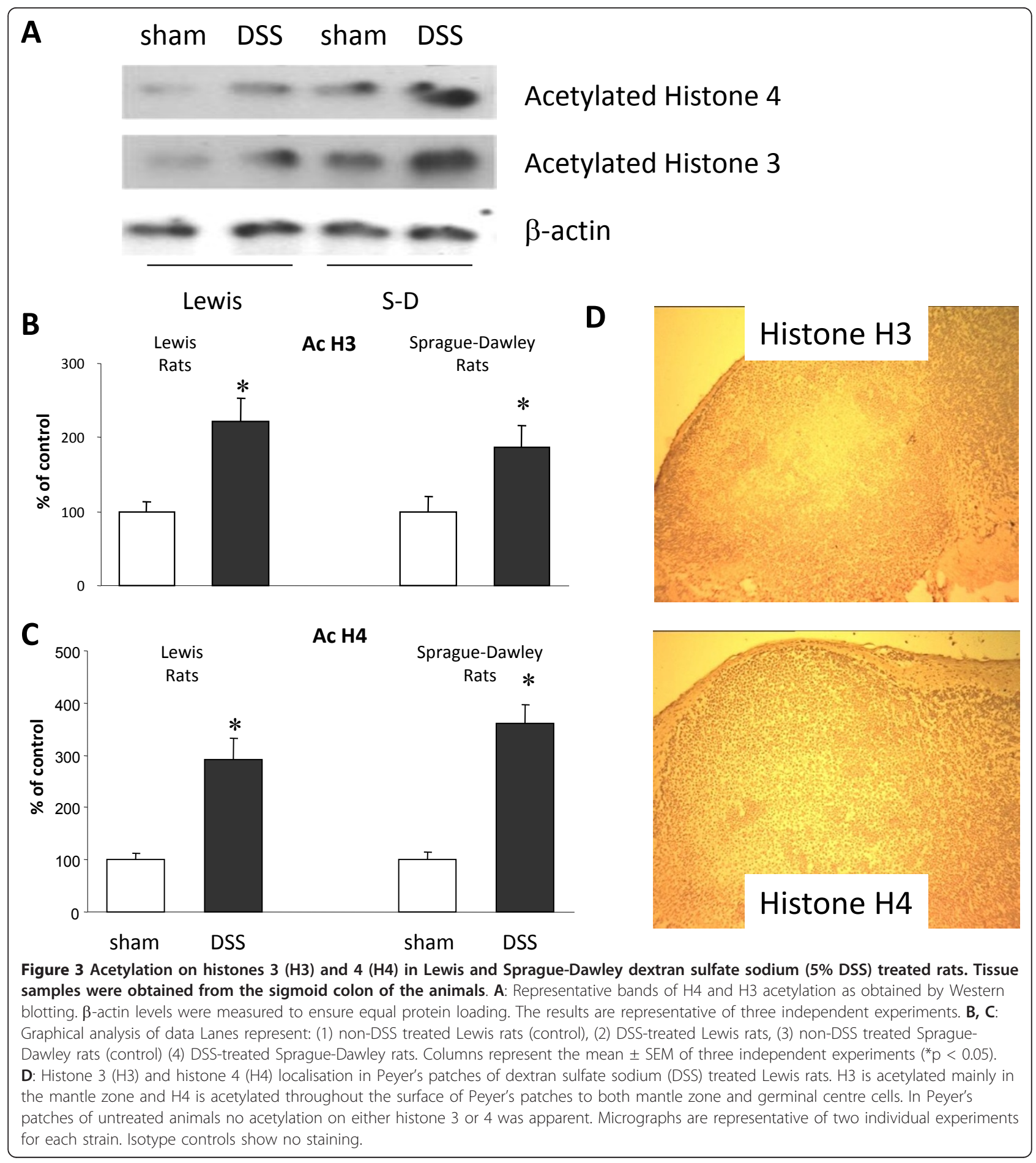

12 in contrast to non-inflamed tissue. In addition, acetylated $\mathrm{H} 4$ was localised to inflamed tissue and to PP in DSS-treated rat models. Within the PP, H3 acetylation was detected in the mantle zone whereas $\mathrm{H} 4$ acetylation was seen in both the periphery and the germinal centre. Finally, acetylation of $\mathrm{H} 4$ was significantly increased in inflamed biopsies and PP from patients with CD.
Enhanced acetylation of H4K5 and K16 was seen in the PP. Acetylation of $\mathrm{K} 5$ and $\mathrm{K} 16$ was localized to the mantle zone whereas acetylation of $\mathrm{K} 8$ and $\mathrm{K} 12$ was localized to both the mantle zone and the germinal center (data not shown). The diversity of IBD and the difficulty in successfully distinguishing between Ulcerative colitis and Crohn's disease underlined the criteria for 


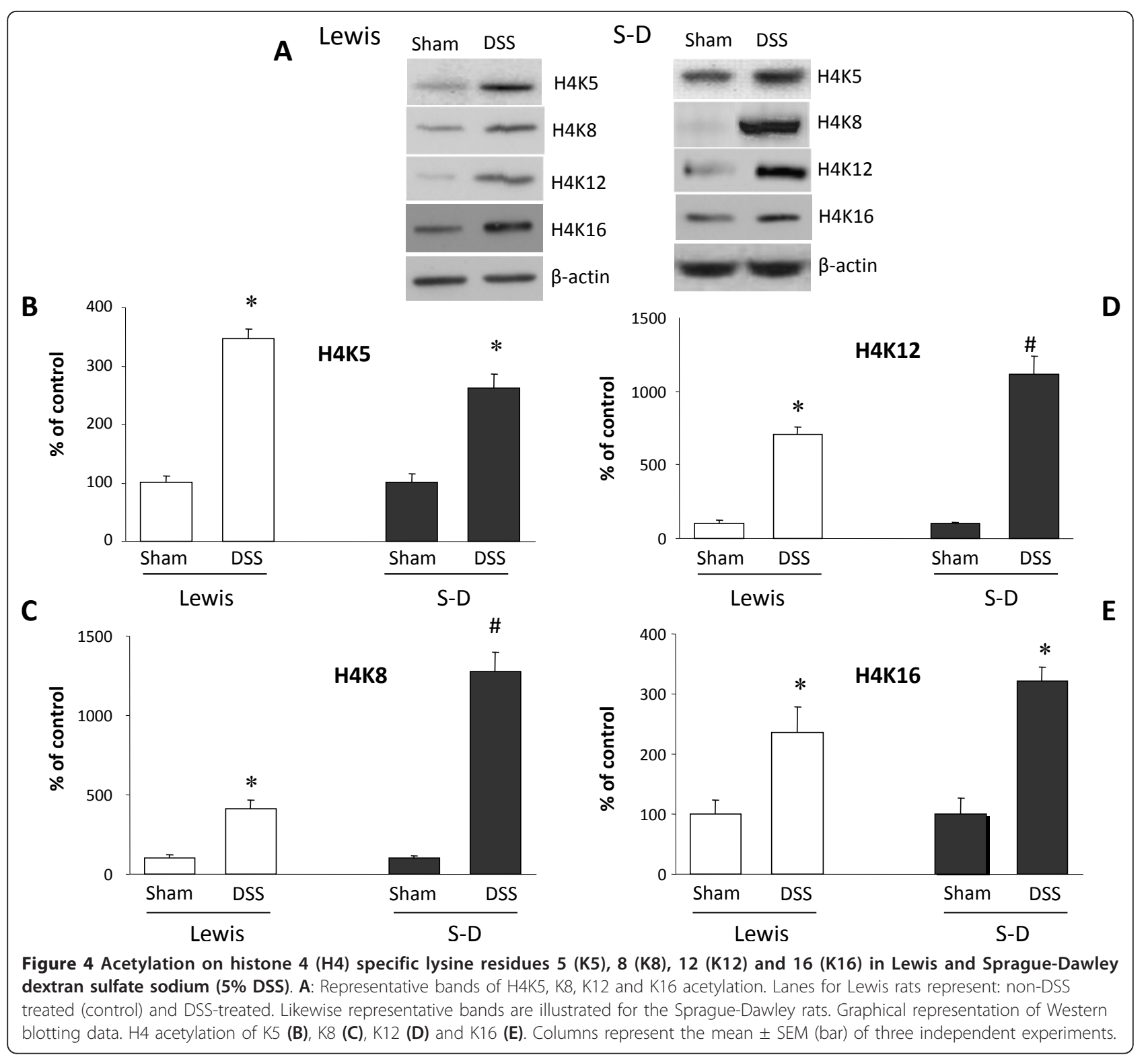

employing two different animal models for studying histone acetylation (TNBS and DSS) associated with Crohn's disease and Ulcerative colitis respectively [30].

Although in many cases it is not clear whether cytokines are the cause or the result of the underlying disease process there is little question that their presence can have profound effects upon gut epithelial cell function and that pro-inflammatory cytokines are key factors in the pathogenesis of Crohn's disease (CD). Activation of nuclear factor kappa B (NF- $\kappa \mathrm{B})$, which is involved in pro-inflammatory cytokine gene transcription, is increased in the intestinal mucosa of CD patients [31]. Modulation of histone acetylation is involved in transcriptional regulation, associated with the $\mathrm{NF}-\kappa \mathrm{B}$ pathway [32-34]. Importantly, either a lack or an excess of NF $-\kappa \mathrm{B}$ can lead to IBD. As enhanced intestinal epithelial permeability may cause IBD by itself, NF- $\kappa \mathrm{B}$ deficiency could underline epithelial barrier function directly by deregulating the expression of proteins involved in cellular adhesion. Alternatively, NF- $\kappa \mathrm{B}$ failure could break the barrier indirectly by compromising the survival of epithelial cells [35]. This might explain the complex molecular mode of action of butyrate in IBD, where for example reports show that butyrate inhibits NF- $\kappa \mathrm{B}$ activation and increases $\mathrm{I} \kappa \mathrm{B} \beta$ levels in vitro in intestinal epithelial cell lines [36]. In gain of function mutations in the Nod2 gene, there is an induction of TH1 and IL-17 secreting $\mathrm{T}$ helper response that 


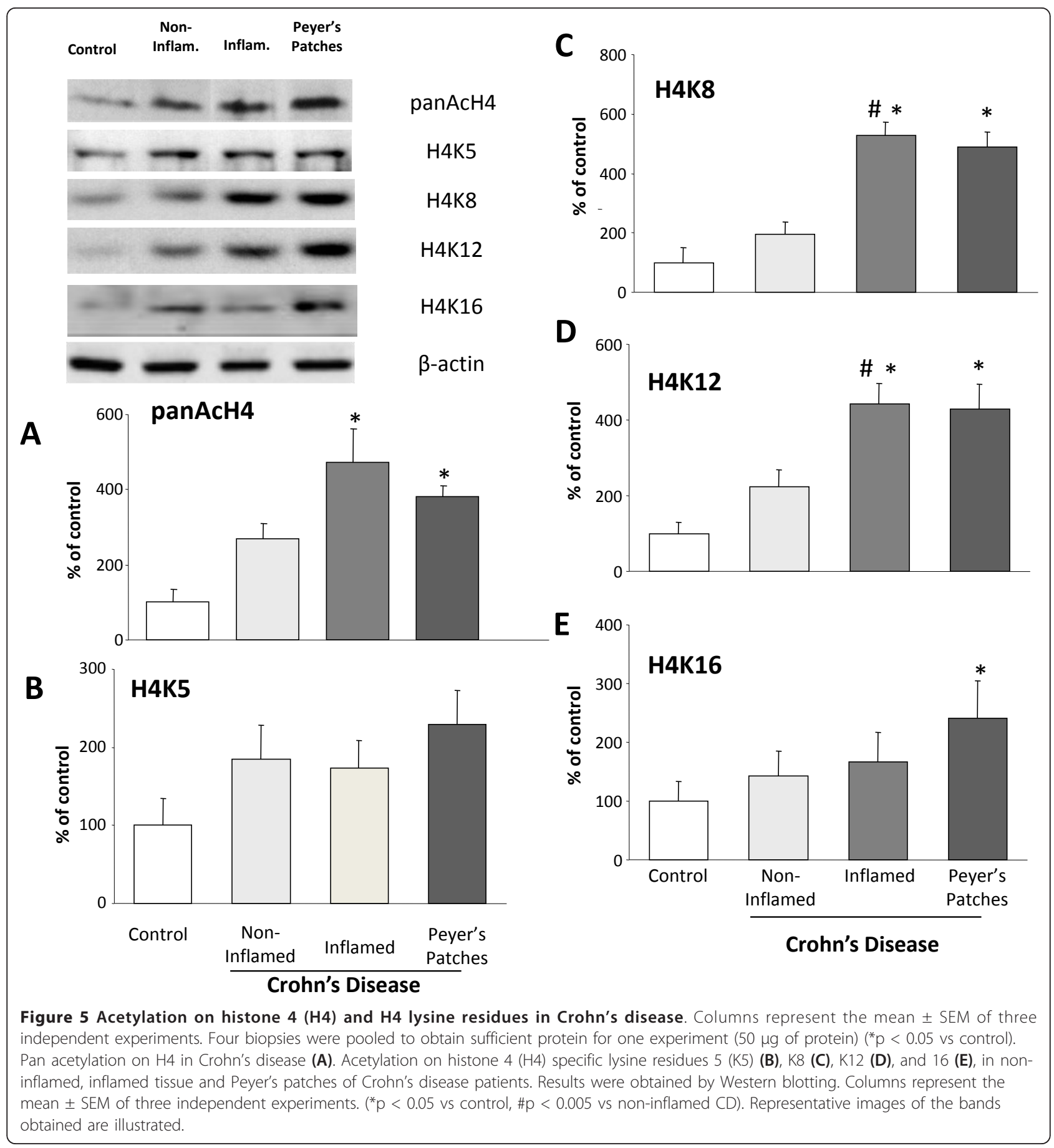

promotes tissue damage and Crohn's disease [37]. On the other hand, loss-of-function mutations compromise NF- $\kappa \mathrm{B}$ activation and TH1 driven colitis [35].

A number of articles demonstrate that acetylation of histone $\mathrm{H} 4$ plays a primary role in the structural changes that mediate enhanced binding of transcription factors to their recognition sites within nucleosomes [38]. In primary airway smooth muscle cells, TNF- $\alpha$ induced histone 4 acetylation and this induction was attenuated by pre-treatment of cells with a glucocorticoid [39]. Finally, variations in global levels of histone marks in different grades, morphologic types, and phenotype classes of invasive breast cancer have been reported to be clinically significant [40]. The use of sodium butyrate, a histone deacetylase inhibitor, in the treatment of IBD lead to the hypothesis that in addition 
to its anti-proliferative action, an effect on histone acetylation could be associated with its therapeutic effects. For example, in human umbilical vein endothelial cells (HUVEC), induction of tissue-type plasminogen activator (t-PA) transcription by butyrate and Trichostatin A was preceded by histone 4 acetylation [41]. Recent evidence revealed that butyrate decreases pro-inflammatory cytokine expression via inhibition of NF- $\kappa \mathrm{B}$ activation and $\mathrm{I} \kappa \mathrm{B} \alpha$ degradation $[14,18,42]$ while it has also been demonstrated that NF- $\kappa \mathrm{B}$ induction of inflammatory gene expression is associated with histone acetylation $[28,34]$ and indeed with p65 acetylation [43]. With the importance of $\mathrm{H} 4$ acetylation having been studied and described in other disease models, experiments were carried out in to investigate whether acetylated histone 4 activity was altered in inflamed and non-inflamed tissue of a TNBS model of colitis. We observed differences in histone 4 acetylation levels between inflamed and non-inflamed tissue particularly with respect to K8 and K12 acetylation. This specificity towards lysine acetylation could be explained by the selective recruitment of transcriptional co-activators containing HAT activity by transcription factors such as NF- $\kappa \mathrm{B}[44,45]$. Although tempting to suggest a cause-and-effect model it is unclear whether increased inflammation leads directly to increased histone acetylation in vivo at specific gene promoters. Further studies will be needed to address this in IBD but preliminary evidence suggests that this may be the case for the GM-CSF promoter in alveolar macrophages from smokers [46]. Also another interesting study investigating the effect of pro-inflammatory cytokines in intestinal alkaline phosphatase (IAP) gene expression comes to further support the possible role of histone acetylation in intestinal inflammation. The authors report both histones 3 and 4 were hyperacetylated in HT-29 cells when they were stimulated with TNF- $\alpha$ or IL- $1 \beta$ concluding that both pro-inflammatory cytokines affect sodium butyrate-induced activation of the IAP gene likely via deacetylation of its promoter region [47].

Macroscopic analysis of tissue from both Lewis and Sprague-Dawley rats treated with 5\% DSS revealed areas of severe inflammation. However, Peyer's patches did not show any signs of inflammation agreeing with previous results showing that the DSS model resembles ulcerative colitis with inflammation present in the descending and sigmoid colon and the rectum but is not apparent along the wall of the small intestine where Peyer's patches are situated. In the DSS model, acetylation of histones 4 and 3 was upregulated in both Lewis and Sprague-Dawley rats. Comparison of acetylated levels between histones 3 and 4 revealed that while both were acetylated, the latter reached significantly higher levels. Similarly, in Peyer's patches of the DSS model, histone 4 acetylation was greater than that of histone 3 . Immunohistochemical investigation of Peyer's patches revealed a distinct pattern of histone acetylation. Acetylation on $\mathrm{H} 3$ was only detected in the mantle zone of Peyer's patches, whilst acetylated H4 occurred in both the periphery and the germinal centre of Peyer's patches. Therefore, it was concluded that acetylation on $\mathrm{H} 3$ could possibly be cell specific, whereas $\mathrm{H} 4$ is generally induced in all cell types present in Peyer's patches (T-cells, B-cells, dendritic cells and macrophages) although this needs to be formally assessed (possibly by counter staining). These data indicate an increase in histone acetylation during gut inflammation. In support, a number of reports show differential $\mathrm{H} 3$ acetylation patterns between TH1 and TH2 cells [48,49].

Acetylation of K8 and K12 is associated with the upregulation of inflammatory genes [28]. In the DSS model of colitis, H4 K8 and K12 were highly acetylated in the Sprague-Dawley rats. These findings were in agreement with previous results documented in vitro [50]. Interestingly, in the Lewis rats, only K12 acetylation was strongly induced. This difference could be attributed to genetic variances between the two rat strains, as discussed by other groups [51,52].

The present study was concluded by measuring $\mathrm{H} 4$ acetylation in Crohn's disease patient biopsies. As with the TNBS model, Peyer's patches, non-inflamed and inflamed biopsies were assessed. Levels of acetylated H4 were most prominent in the inflamed biopsies, followed by those in Peyer's patches albeit to a lesser extent. Acetylation was also detectable in the non-inflamed mucosa of Crohn's disease patients. The results for acetylation on H4 lysines in Crohn's disease were very similar to those obtained in the TNBS treated animals. K5 and K16 were only slightly acetylated in all samples, with the inflamed and non-inflamed samples presenting no significant difference in acetylation. Peyer's patches showed the highest levels of K5 and K16 acetylation. Finally, in biopsies of inflamed bowel and in Peyer's patches of Crohn's disease patients, K8 and K12 were both significantly acetylated. Acetylation on lysine residues in the non-inflamed biopsies was only slightly upregulated. The results suggested that although pan acetylation on $\mathrm{H} 4$ in the Peyer's patches is probably not cell specific, it is possible that acetylation of its specific lysine residues is cell type dependent. This could also explain the significant increase in $\mathrm{K} 8$ and $\mathrm{K} 12$ acetylation revealed by Western blotting. An increased Treg number in Peyer's patches indicates that they have a very important niche in the peripheral gut, where new encounters with antigens are very critical. In this respect, it seems natural that Treg are more numerous in Peyer's patches as it is in the gut that antigens to cross the intestinal barrier are to be processed and exert 
their effect, and thus it is an area where essential antigenic surveillance is taking place [53].

Site specific histone acetylation and deacetylation have been associated in more recent years with a number of different functions such as nucleosome assembly, heterochromatin silencing, transcription and gene repression [54]. The human chromatin assembly factor 1 (CAF-1) complex co-purifies with histone $\mathrm{H} 4$ modified at sites that are indicative of recent synthesis. Acetylation is observed at $\mathrm{K} 5, \mathrm{~K} 8$ and/or K12 but not at K16 [55]. In yeast H4K16 appears to be critical for the silencing information regulator protein (Sir) binding because the interaction between full length Sir3 and an H4 peptide in vitro is abolished by acetylation of lysine 16 but not other lysines [56]. Another example of site specific lysine acetylation involves the SMRT mammalian corepressor. SMRT preferentially binds to the unacetylated histone 4 tail and its binding is dependent on deacetylated H4K5 [57]. Finally, another example of the effect of specific lysine residue acetylation in gene function is the observation that with the coding region of ERG11, an active gene, deacetylases Hos 2 and Rpd3 redundantly deacetylate all lysines in histone 4 and $\mathrm{H} 4$ tails except for H4K16, which is deacetylated primarily by Hos2 [58]. Precise patterns of acetylation at promoters, therefore, may be recognized by particular transcription factors because specific combinations of hypoacetylated residues at genes correlate with specific expression profiles over a variety of conditions [54].

Paradoxically, HDAC inhibitors are used in the treatment of IBD. This may reflect either an anti-proliferative effect seen with high, non-specific doses of HDAC inhibitors or an effect on the acetylation status of nonhistone proteins e.g. tubulin and transcription factors such as NF- $\kappa$ B and GATA $[20,59,60]$. Recent reports, however, show that administration of an HDAC inhibitor in vivo increased Foxp3 gene expression, as well as the production and the suppressive function of regulatory $\mathrm{T}$ cells (Treg cells). It has been shown that HDAC inhibition therapy in vivo enhanced Treg-mediated suppression of a homeostatic proliferation and decreased IBD through Treg-dependent effects [61]. These results may, at least in part, reflect the activation of regulatory $\mathrm{T}$-cells involved in active NF- $\kappa \mathrm{B}$ suppression (and increased histone acetylation) of inflammation primarily induced in the Peyer's patches [62].

The results presented here are indicative of the importance of histone 4 acetylation in the expression of inflammatory genes in inflammatory diseases, such as IBD. Whether this is causal or downstream to activation of inflammation is unclear but suggests that HAT inhibitors may be useful in treatment. Deacetylase inhibitors in vivo, such as Belinostat (PXD101) and Phenylbutyrate, are currently used in clinical trials. However, most clinical trials have not had much success either due to the disease being stable or due to adverse effects of the drug [63]. The mechanism might be better understood when the target proteins (histone or non-histone) of these compounds are identified.

The present preliminary studies aim to provide further understanding in the role that histone acetylation plays in the regulation of inflammation. Future studies should examine the activity of specific HATs and HDACs in individual immune and resident cells types. It is, therefore, possible to speculate that further understanding of the role of histone modifications in IBD may lead to new therapeutic strategies in the treatment of IBD and explain the therapeutic utility of current treatment.

\section{Acknowledgements}

This work was funded by the University of Bedfordshire and GlaxoSmithKline (UK).

\section{Author details}

${ }^{1}$ Airways Disease Section, National Heart \& Lung Institute, Imperial College London, Dovehouse Street, London, SW3 6LY, UK. ${ }^{2}$ School of Health and Biosciences, University of East London, Stratford Campus, Romford Road, London, E15 4LZ, UK. ${ }^{3}$ Gastroeintestinal Laboratory, Rayne Institute, St. Thomas Hospital, London, SE1 7EH, UK.

\section{Authors' contributions}

LGT performed all experiments and drafted the manuscript. KI participated in the histone extraction methods. JJP provided clinical and animal samples. IMA participated in the design and coordination of the study and to manuscript writing. NP participated in the design and coordination of the study. All authors read and approved the final manuscript.

\section{Competing interests}

The authors declare that they have no competing interests.

Received: 12 April 2010 Accepted: 27 January 2011

Published: 27 January 2011

\section{References}

1. Baumgart DC, Carding SR: Inflammatory bowel disease: cause and immunobiology. Lancet 2007, 369(9573):1627-1640.

2. D'Haens G, Daperno M: Advances in biologic therapy for ulcerative colitis and Crohn's disease. Curr Gastroenterol 2006, 8(6):506-512.

3. Travis S: Advances in therapeutic approaches to ulcerative colitis and Crohn's disease. Curr Gastroenterol 2005, 7(6):475-484.

4. Neurath M, Fuss I, Strober W: TNBS-colitis. Int Rev Immunol 2000, 19:51-62

5. Fujno K, Takami Y, dela Fuente SG, Ludwig KA, Mantyh CR: Inhibition of the vanilloid receptor subtype- 1 attenuates TNBS-colitis. $J$ of Gastrointestinal Surg 2004, 8(7):842-848.

6. Dohi T, Fujihashi K, Rennert PD, Iwatani K, Kiyoto H, McGhee JR: Hapteninduced colitis is associated with colonic patch hypertrophy and $\mathrm{T}$ Helper cell-2-type responses. J Exp Med 1999, 189:1169-1179.

7. Alex P, Zachos NC, Nguyen T, Gonzales L, Chen TE, Conklin LS, Centola M, Li X: Distinct cytokine patterns identified from multiplex profiles of murine DSS and TNBS-induced colitis. Inflammatory Bowel Diseases 2008, 15(3):341-352

8. Zaph C, Troy AE, Taylor BC, Berman-Booty LD, Guild KJ, Du Y, Yost EA, Gruber AD, May MJ, Greten FR, Eckmann L, Karin M, Artis D: Epithelial-cellintrinsic IKK- $\beta$ expression regulates intestinal immune homeostasis. Nature 2007, 446:552-556.

9. Nenci A, Becker C, Wullaert A, Gareus R, van Loo G, Danese S, Huth M, Nikolaev A, Neufert C, Madison B, Gumucio D, Neurath MF, Pasparakis M: Epithelial NEMO links innate immunity to chronic intestinal inflammation. Nature 2007, 446:557-561. 
10. Murano M, Maemura K, Hirata I, Toshina K, Nishikawa T, Hamamoto N Sasaki S, Saitoh O, Katsu K: Therapeutic effect of intracolonically administered nuclear factor kappa B (p65) antisense oligonucleotide on mouse dextran sulphate sodium (DSS)-induced colitis. Clin Exp Immunol 2000, 120:51-58

11. Herfarth H, Brand K, Rath HC, Rogler G, Scholmerich J, Falk W: Nuclear factor-kappa B activity and intestinal inflammation in dextran sulphate sodium (DSS)-induced colitis in mice is suppressed by gliotoxin. Clin Exp Immunol 2000, 120:59-65.

12. Fitzpatrick $L R$, Wang J, Le $T$ : In vitro and in vivo effects of gliotoxin, a fungal metabolite: efficacy against dextran sodium sulfate-induced colitis in rats. Dig Dis Sci 2000, 45:2327-2336.

13. Rahman I, Marwick J, Kirkham P: Redox modulation of chromatin remodeling: impact on histone acetylation and deacetylation, NF-KB and pro-inflammatory gene expression. Biochem Pharmacol 2004, 68(6):1255-1267.

14. Place RF, Noonan EJ, Giardina C: HDAC inhibition prevents NF-kB activation by suppressing proteasome activity: Down-regulation of proteasome subunit expression stabilizes IkBa. Biochem Pharmacol 2005, 70:394-406.

15. Siavoshian S, Segain JP, Kornprobst M, Bonnet C, Cherbut C, Galmiche JP, Blottiere HM: Butyrate and trichostatin A effects on the proliferation/ differentiation of human intestinal epithelial cells: induction of cyclin D3 and p21 expression. Gut 2000, 46:507-514.

16. Glauben R, Batra A, Fedke I, Zeitz M, Lehr HA, Leoni F, Mascagni $P$, Fantuzzi G, Dinarello CA, Siegmund B: Histone hyperacetylation is associated with amelioration of experimental colitis in mice. J Immunol 2006, 176:5015-5022

17. Roy CC, Kien CL, Bouthillier L, Levy E: Short-chain fatty acids: ready for prime time? Nutr Clin Pract 2006, 21(4):351-366.

18. Park JS, Lee EJ, Lee JC, Kim WK, Kim HS: Anti-inflammatory effects of short chain fatty acids in IFN-gamma-stimulated RAW 264.7 murine macrophage cells: involvement of NF-kappaB and ERK signalling pathways. Int Immunopharmacol 2007, 7(1):70-77.

19. Xu WS, Parmigiani RB, Marks PA: Histone deacetylase inhibitors: molecular mechanisms of action. Oncogene 2007, 26(37):5541-5552.

20. Bhavsar P, Ahmad T, Adcock IM: The role of histone deacetylases in asthma and allergic diseases. J Allergy Clin Immunol 2008, 121(3):580-584

21. Matthews JG, Ito K, Barnes PJ, Adcock IM: Defective glucocorticoid receptor nuclear translocation and altered histone acetylation patterns in glucocorticoid-resistant patients. J Allergy Clin Immunol 2004, 113:1100-1108.

22. Li L, Leung DYM, Strand MJ, Golevs E: ATF2 impairs glucocorticoid receptor mediated transactivation in human $\mathrm{CD}^{+} \mathrm{T}$ cells. Blood 2007, 110(5):1570-1577.

23. Fraga MF, Ballestar E, Villar-Garea A, Boix-Chornet M, Espada J, Schotta G, Bonaldi T, Haydon C, Ropero S, Petrie K, lyer NG, Pérez-Rosado A, Calvo E, Lopez JA, Cano A, Calasanz MJ, Colomer D, Piris MA, Ahn N, Imhof A, Caldas C, Jenuwein T, Esteller M: Loss of acetylation at Lys16 and trimethylation at Lys 20 of histone $\mathrm{H} 4$ is a common hallmark of human cancer. Nat Gen 2005, 37(4):391-400.

24. Morris GP, Beck PL, Herridge MS, Depew WT, Szewczuk MR, Wallace JL: Hapten-induced models of chronic inflammation and ulceration in the rat colon. Gastroenterol 1989, 96:795-803.

25. Vowinkel T, Kalogeris TJ, Mori M, Krieglstein CF, Granger DN: Impact of dextran sulfate sodium load on the severity of inflammation in experimental colitis. Dig Dis Sci 2004, 49(4):556-564.

26. Ellis RD, Goodlad JR, Limb GA, Powell JJ, Thompson RP, Punchard NA: Activation of nuclear factor kappa B in Crohn's disease. Inflamm Res 1998, 47:440-445.

27. Ito K, Barnes PJ, Adcock IM: Histone acetylation and histone deacetylation. Methods in Molecular Medicine. Asthma: Mechanisms and Protocols 2000, 44:309-319.

28. Ito K, Barnes PJ, Adcock IM: Glucocorticoid receptor recruitment of histone deacetylase 2 inhibits interleukin- $1 \beta$-induced histone $\mathrm{H} 4$ acetylation on lysines 8 and 12. Mol Cell Biol 2000, 20(18):6891-6903.

29. Ito K, Caramori G, Lim S, Oats T, Chung KF, Barnes PJ, Adcock IM: Expression and activity of histone deacetylases in human asthmatic airways. Am J Respir Crit Care Med 2002, 166(3):392-396.

30. Neurath MF, Finotto S, Fuss I, Boirivant M, Galle PR, Strober W: Regulation of T-cell apoptosis in inflammatory bowel disease: to die or not to die, that is the mucosal question. Trends Immunol 2001, 22:21-26.
31. Schreiber S: Inflammatory bowel disease: Immunologic concepts. HepatoGastroenterol 2000, 47:15-28.

32. Adcock IM, Cosio B, Tsaprouni L, Barnes PJ, Ito K: Redox regulation of histone deacetylases and glucocorticoid-mediated inhibition of the inflammatory response. Antioxid Redox Signal 2005, 7(1-2):144-152.

33. Ito K, Yamamura S, Essilfie-Quaye S, Cosio B, Ito M, Barnes PJ, Adcock IM: Histone deacetylase 2-mediated deacetylation of the glucocorticoid receptor enables NF-kappa B suppression. J Exp Med 2006, 203(1):7-13

34. Ashburner BP, Westerheide SD, Baldwin AS Jr: The p65 (RelA) subunit of NF-KB interacts with the histone deacetylase (HDAC) corepressors HDAC1 and HDAC2 to negatively regulate gene expression. Molecular and Cellular Biology 2001, 21:7065-7077.

35. Ben-Neriah Y, Schmidt-Supprian M: Epithelial NF-kappaB maintains host gut microflora homeostasis. Nat Immunol 2007, 8(5):479-481.

36. Hamer HM, Jonkers D, Venema K, Vanhoutvin S, Troost FJ, Brummer RJ: Review article: the role of butyrate on colonic function. Aliment Pharmacol Ther 2008, 27(2):104-119.

37. Maeda S, Hsu LC, Liu H, Bankston LA, limura M, Kagnoff MF, Eckmann L, Karin M: Nod2 mutation in Crohn's disease potentiates NF-kappaB activity and IL-1beta processing. Science 2005, 307(5710):734-738.

38. Vettese-Dadey M, Grant PA, Hebbes TH, Crane-Robinson C, Allis CD, Workman JL: Acetylation of histone $\mathrm{H} 4$ plays a primary role in enhancing transcription factor binding to nucleosomal DNA in vitro. EMBO J 1996, 15(10):2508-2518.

39. Nie M, Knox AJ, Pang L: Beta-2 Adrenoreceptor agonists, like glucocorticoids repress eotaxin gene transcription by selective inhibition of histone $\mathrm{H} 4$ acetylation. J Immunol 2005, 175:478-486.

40. Elsheikh SE, Green AR, Rakha EA, Powe DG, Ahmed RA, Collins HM, Soria D, Garibaldi JM, Paish CE, Ammar AA, Grainge MJ, Ball GR, Abdelghany MK Martinez-Pomares L, Heery DM, Ellis IO: Global Histone Modifications in Breast Cancer Correlate with Tumor Phenotypes, Prognostic Factors, and Patient Outcome. Cancer Res 2009, 69(9):3802-3809.

41. Arts J, Lansink M, Grimbergen J, Toet KH, Kooistra T: Stimulation of tissuetype plasminogen activator gene expression by sodium butyrate and trichostatin A in human endothelial cells involves histone acetylation. Biochem J 1995, 310:171-176.

42. Song M, Xia B, Li J: Effects of topical treatment of sodium butyrate and 5-aminosalicylic acid on expression of trefoil factor 3, interleukin 1 beta, and nuclear factor kappaB in trinitrobenzene sulphonic acid induced colitis in rats. Postgrad Med J 2006, 82(964):130-135.

43. Chen L, Fischle W, Verdin E, Greene WC: Duration of nuclear NF-kappaB action regulated by reversible acetylation. Science 2001, 293:1653-1657.

44. Smoak KA, Cidlowski JA: Mechanisms of glucocorticoid receptor signalling during inflammation. Mechs Age Dev 2004, 125:697-706.

45. Hoffmann A, Natoli G, Ghosh S: Transcriptional regulation via the NF-kB signalling module. Oncogene 2006, 25:6706-6716.

46. Ito K, Lim S, Caramori G, Chung KF, Barnes PJ, Adcock IM: Cigarette smoking reduces histone deacetylase 2 expression, enhances cytokine expression, and inhibits glucocorticoid actions in alveolar macrophages. FASEB J 2001, 15:1110-1112.

47. Malo MS, Biswas S, Abedrapo MA, Yeh L, Chen A, Hodin RA: The proinflammatory cytokines, IL-1 $\beta$ and TNF- $\alpha$, inhibit intestinal alkaline phosphatase gene expression. DNA and Cell Biology 2006, 25(12):684-695.

48. Wang L, Kametani Y, Katano I, Habu S: T-cell specific enhancement of histone $\mathrm{H} 3$ acetylation in $5^{\prime}$ flanking region of the IL-2 gene. Biochem and Bipophys Commun 2005, 331(2):589-594.

49. Letting DL, Rakowski C, Weiss MJ, Blobel GA: Formation of a TissueSpecific Histone Acetylation Pattern by the Hematopoietic Transcription Factor GATA-1. Mol and Cell Biol 2003, 23(4):1334-1340.

50. Wako T, Houben A, Furushima-Shimogawara R, Belyaev ND, Fukui K. Centromere-specific acetylation of histone $\mathrm{H} 4$ in barley detected through three-dimensional microscopy. Plant Mol Biol 2003, 51(4):533-541.

51. Quary S, Bizat N, Altairac S, Menetrat H, Mittoux V, Conde F, Hantraye P, Brouillet $\mathrm{E}$ : Major strain differences in response to chronic systemic administration of the mitochondrial toxin 3-nitropropionic acid in rats: implications of neuroprotection studies. Neuroscience 2000, 97:521-530.

52. Jurado F, Bellon JM, Golitsin A, Gimero MJ, Pascual G, Bujan J: Role of macrophages in myocardial apoptosis following cardiac transplant. Influence of immunosuppressive treatment. Histology and Histopathology 1999, 14:1033-1043. 
53. Ejsing-Duun M, Josephsen J, Aasted B, Buschard K, Hansen AK: Dietary Gluten Reduces the Number of Intestinal Regulatory T Cells in Mice. Scandinavian Journal of Immunol 2008, 67:553-559.

54. Shahbazian MD, Grunstein M: Functions of site-specific histone acetylation and deacetylation. Annual Review of Biochem 2007, 76:75-100

55. Verreault A, Kaufman PD, Kobayashi R, Stillman B: Nucleosome assembly by a complex of CAF-1 and acetylated histones H3/H4. Cell 1996 , 87:95-104.

56. Liou GG, Tanny JC, Kruger RG, Walz T, Moazed D: Asssembly of the SIR complex and its regulation by O-acetyl-ADP-ribose, a product of NADdependent histone deacetylation. Cell 2005, 121:515-527.

57. Hartman HB, Yu J, Alenghat T, Ishizuka T, Lazar MA: The histone binding code of nuclear receptor co-repressors matches the substrate specificity of histone deacetylase 3. EMBO Rep 2005, 6:445-451.

58. Wang A, Kurdistani SK, Grunstein M: Requirement of Hos2 histone deacetylase for gene activity in yeast. Science 2002, 298(5597):1412-1414.

59. Adcock IM, Caramori G: Cross talk between pro-inflammatory transcription factors and glucocorticoids. Immunol and Cell Biol 2001. 79:376-384.

60. Dokmanovic M, Clarke C, Marks PA: Histone deacetylase inhibitors: Overview and perspectives. Mol Cancer Res 2007, 5(10):981-989.

61. Tao R, de Zoeten EF, Özkaynak E, Chen C, Wang L, Porrett PM, Li B, Turka LA, Olson EN, Greene MI, Wells AD, Hancock WW: Deacetylase inhibition promotes the generation and function of regulatory $\mathrm{T}$ cells. Nature Medicine 2007, 13(11):1299-1307.

62. Tsuji NM, Mizumachi K, Kurisaki J: Interleukin-10-secreting Peyer's patch cells are responsible for active suppression in low-dose oral tolerance. Immunology 2001, 103(4):458-464.

63. Ma X, Ezzeldin HH, Diasio RB: Histone deacetylase inhibitors: Current status and overview of recent clinical trials. Drugs 2009, 69(14):1911-1934.

doi:10.1186/1476-9255-8-1

Cite this article as: Tsaprouni et al:: Differential patterns of histone acetylation in inflammatory bowel diseases. Journal of Inflammation 2011 8:1.

\section{Submit your next manuscript to BioMed Central} and take full advantage of:

- Convenient online submission

- Thorough peer review

- No space constraints or color figure charges

- Immediate publication on acceptance

- Inclusion in PubMed, CAS, Scopus and Google Scholar

- Research which is freely available for redistribution 